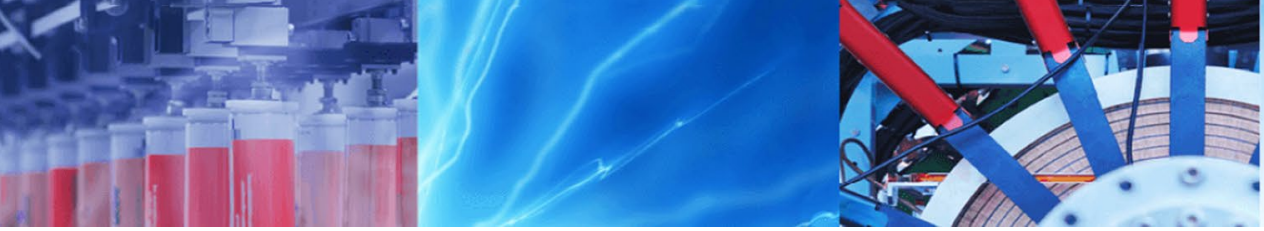

Research Article

\title{
Development of oxygen vacancies and surface defects in Mn-doped ZnO nanoflowers for enhancing visible light photocatalytic activity
}

\author{
Nita Raskar ${ }^{1} \cdot$ Dnyaneshwar Dake $^{1} \cdot$ Hari Khawal $^{1} \cdot$ Uday Deshpande $^{2} \cdot \mathrm{K}_{\text {. Asokan }}^{3} \cdot$ Babasaheb Dole $^{1}$ (D)
}

Received: 28 February 2020 / Accepted: 10 June 2020 / Published online: 21 July 2020

(c) Springer Nature Switzerland AG 2020

\begin{abstract}
Pure and Mn-doped ZnO nanoflowers were successfully synthesized by the hydrothermal technique. Doping of Mn into $\mathrm{ZnO}$ lattice exhibits formation of oxygen vacancies and surface modifications into $\mathrm{ZnO}$ lattice was investigated by XPS spectra and AFM analysis. During the photocatalytic performance, vacancies create the trap centers for photogenerated electrons hence the electron-hole recombination is effectively inhibited. These formed oxygen vacancies along with enhanced surface area are due to Mn doping, resulted in effective photodegradation of methylene blue solution under solar light irradiation. The degradation efficiency for methylene blue dye exceeds $82 \%$ after 120 min under solar light irradiation, also the catalytic performance of $\mathrm{Mn}$-doped $\mathrm{ZnO}$ nanoflowers retains even after 4 cycles.
\end{abstract}

Keywords $\mathrm{ZnO}$ nanoflowers · Oxygen vacancies · Photocatalytic degradation · Surface defects

\section{Introduction}

At present zinc oxide $(\mathrm{ZnO})$ is the most promising semiconductor material which has been studied extensively in the last few decades for distinct applications such as photocatalysis, optics, electronics, semiconductor materials, piezoelectric, magnetic and biomedicine due to its multifunctional nature and properties. ZnO nanomaterials have fascinated great attention owing to their low cost, ease to fabrication of various nanostructured materials, chemical and thermal stability, photocatalytic activities, and wide band gap semiconductor, unique optical, electrical, structural and physical properties. One-dimensional (1D) semiconductor nanomaterials such as nanowires, nanorods, nanobelts, and nanoflowers have been used for technology and industrial applications. In today's research on photocatalytic activity, these nanostructures are most significant nanomaterials due to their high surface to volume ratio and smaller band gap [1-3]. To enhance the photocatalytic activities, the following parameters affect photocatalytic efficiencies such as a surface area to volume ratio, porosity, oxygen vacancy, surface defects, conductivity, thermal stability, chemical stability, high mobility and low band gap [4-6]. Recently $\mathrm{ZnO}$ is strong semiconducting nanomaterial for degradation of methylene blue, methyl orange, rhodamine- $B$, and congo red, etc. organic dyes and purification of water owing to its high reactivity, environment-friendly nature, non-toxic and cost-effective. Therefore, researchers are interested to achieve aforesaid parameters and synthesized $\mathrm{ZnO}$ nanomaterials by diverse methods such as metal-nonmetal doping, surface modification via organic materials, combining semiconductor oxide nanoparticles with conducting polymers, irradiation source, $\mathrm{pH}$, addition of carboxylic compounds, distinct composites with $\mathrm{ZnO} / \mathrm{TiO}_{2} / \mathrm{GO}$, using various surfactant for different morphology (template method), etc. to degrade highly toxic dyes [7-11].

$\triangle$ Babasaheb Dole, drbndole.phy@gmail.com | ${ }^{1}$ Advanced Materials Research Laboratory, Department of Physics, Dr. Babasaheb Ambedkar Marathwada University, Aurangabad, Maharashtra 431004, India. ${ }^{2}$ UGC-DAE Consortium for Scientific Research, Indore Centre University Campus, Khandwa Road, Indore 452017, India. ${ }^{3}$ Materials Science, Inter-University Accelerator Centre, Aruna Asaf Ali Marg, New Delhi 110 067, India. 
However, the disadvantage of $\mathrm{ZnO}$ nanomaterials is due to its large band gap of $3.37 \mathrm{eV}$, therefore, it absorbs light only in the UV region that is only about $5 \%$ of the solar spectrum and it is the challenge for researchers. Therefore, the effective use of solar energy still remains a challenge in photocatalytic applications. Due to this problem, we have introduced solar radiation to study the degradation of methylene blue using $\mathrm{ZnO}$ thin film. To improve the photocatalytic activity of $\mathrm{ZnO}$ in visible radiation, it is necessary to either reduce its band gap or introduce intermediate donor levels with the doping of transition metals. In our preceding publication, we have reported work on nanorods [12] but in the present work, we have prepared nanoflowers because they are highly reactive than nanorods due to their high surface area actively participated in photocatalytic reaction. The doping of transition metals namely $\mathrm{Mn}, \mathrm{Ni}, \mathrm{Ag}, \mathrm{Cu}, \mathrm{Co}, \mathrm{La}, \mathrm{Ce}$, $\mathrm{Au}$, etc. in $\mathrm{ZnO}$ lattice helps the growth of one-dimensional single-crystalline nanostructure on the glass substrate and also reduces the band gap of semiconductor material. Furthermore this doping into the $\mathrm{ZnO}$ lattice introduces point defects viz. oxygen and zinc vacancies thereby inducing intermediate bands in the forbidden bandgap of $\mathrm{ZnO}$ [13-16] These interesting changes in properties of $\mathrm{Mn}$-doped $\mathrm{ZnO}$ have their own importance in research fields, promoting to study the photocatalytic activity of Mn-doped ZnO nanocrystals [17].

There are many methods are available for the synthesis of $\mathrm{ZnO}$ nanoflowers such as dip coating technique [18], sol-gel and spin coating [19], chemical bath deposition [20], chemical vapor deposition [21], hydrothermal [22]. We have selected the hydrothermal technique to synthesis $\mathrm{Mn}$-doped $\mathrm{ZnO}$ nanoflowers because it is a cost-effective and most appropriate technique for getting fine morphology of one-dimensional single crystalline material. To study the effect of photocatalytic activity of pure and $\mathrm{Mn}$-doped $\mathrm{ZnO}$ nanoflowers under solar light may change optical, electrical and morphological properties of $\mathrm{ZnO}$ because their atomic radii are almost equal and properties are influenced by the quantum confinement of electronic states of bulk $\mathrm{ZnO}$ are due to doping of transition metals [23]. Here, we report our work on the development of oxygen vacancies and surface defects into pure and $\mathrm{Mn}$-doped $\mathrm{ZnO}$ nanoflowers in an effective approach. All samples of pure and $\mathrm{Mn}$ doped $\mathrm{ZnO}$ nanoflowers exhibit high photocatalytic activity and good stability during the photocatalytic performance. We have further investigated the crystal structure, grain size, morphology of the as-prepared $\mathrm{Mn}$-doped $\mathrm{ZnO}$ samples by X-ray diffraction and surface elemental composition and surface state by XPS spectroscopy.

\section{Experimental details}

\subsection{Material synthesis}

Pure and $\mathrm{Mn}$-doped $\mathrm{ZnO}$ nanoflower thin films were grown on a glass substrate by hydrothermal technique successfully. For the synthesis of $\mathrm{Mn}$-doped $\mathrm{ZnO}, 1 \mathrm{M}$ Zinc acetate dihydrate, $0.04 \mathrm{M}$ manganese chloride and $1 \mathrm{M}$ of Hexamethylenetetramine (HMTA) were dissolved separately in distilled water. The HMTA solution was added in Zinc solution and dropwise ammonia was added to clear the precipitate $(\mathrm{pH} \sim 10)$ and stirred this solution for $2 \mathrm{~h}$. For the deposition of thin films firstly ultrasonicated the glass substrate using $\mathrm{HCl}$ in an ultrasonic cleaner for $2 \mathrm{~h}$. The substrate was dried and kept aligned in Teflon lined stainless steel autoclave (100 $\mathrm{ml}$ capacity) after that above solution was transferred into the autoclave. Sealed the autoclave and kept in a muffle furnace at $70^{\circ} \mathrm{C}$ for $6 \mathrm{~h}$. Deposited films were cooled followed by room temperature and then washed with distilled water. After washing, deposited films were dried at room temperature. Samples were dehydrated and demoisturized at $110^{\circ} \mathrm{C}$ for $3 \mathrm{~h}$ in HAMCO tubular furnace. The same synthesis procedure was used for the preparation of pure $\mathrm{ZnO}$ samples.

\subsection{Dye degradation activity}

The photocatalytic performance of pure and $4 \% \mathrm{Mn}$-doped $\mathrm{ZnO}$ thin films were examined by the photocatalytic decomposition of Methylene Blue (MB) in an aqueous suspension under solar light irradiation. In a typical experiment $(1 \times 1)$ $\mathrm{cm}^{2}$ of pure and $4 \% \mathrm{Mn}$-doped $\mathrm{ZnO}$ catalyst film was suspended in $0.5 \mathrm{mg} \mathrm{MB}$ in $100 \mathrm{ml}$ deionized water solution. The catalytic thin-film suspension was stirred for $10 \mathrm{~min}$ in dark and then the system was exposed under solar light irradiation with continuous stirring using a magnetic stirrer. Solar light irradiation was carried out from 12 p.m. to 3 p.m. during the winter season in Aurangabad, Maharashtra, India. The latitude and longitude are $19.85^{\circ} \mathrm{N}$ and $75.35^{\circ} \mathrm{E}$ respectively. The average sunlight intensity was found to be around $600 \mathrm{~W} / \mathrm{m}^{2}$. To compare the photocatalytic activity of both pure and $\mathrm{Mn}$-doped $\mathrm{ZnO}$ catalysts, the experiment was conducted simultaneously to avoid errors arising due to fluctuations in solar intensity. The solution was collected for $20 \mathrm{~min}$ of time intervals and analyzed by UV-visible spectroscopy. Also for further comparison the photo catalytic degradation of 4-nitrophenol was studied (ESI).

\subsection{Material characterizations}

The structural parameters were investigated by XRD using D-8 advanced diffractometer (Bruker AXS, Germany) with 
a monochromatic $\mathrm{CuK}_{\mathrm{a}}$ radiation source with wavelength $(\lambda=1.54 \AA)$ and scintillator detector at a scanning rate of $1^{\circ}$ per minute. The effective concentration and binding-state of the ions in the pure and $\mathrm{Mn}$-doped $\mathrm{ZnO}$ samples were characterized by X-ray photoelectron spectroscopy (XPS) (ESCA-LAB 250 Xi, Thermo-VG Scientific). Defect states and fluorescence properties of pure and $\mathrm{Mn}$-doped $\mathrm{ZnO}$ samples were demonstrated using the UV-Vis spectrometer with an LED lamp (Avantes Spec-ULSi2048L-USB2). The surface morphology of as-prepared samples was verified by scanning electron microscopy (SEM) with resolution 5-10 $\mu \mathrm{m}$. The absorption spectrum and energy band gap was measured using a UV-Vis spectrometer (Avantes Spec-ULSi2048L-USB2).

\section{Results and discussion}

\subsection{Structure parameters}

Lattice parameters, crystalize size, lattice strain, the volume of the unit cell and c/a ratio of the $\mathrm{Zn}_{1-\mathrm{x}} \mathrm{Mn}_{\mathrm{x}} \mathrm{O}$ with $x=0.00$ and 0.04 nanoflowers were examined using $X$-ray diffraction patterns along with Rietveld refinement technique. It was found that after doping of $\mathrm{Mn}$ into $\mathrm{ZnO}$ lattice, the aspect ratio of the diffraction peaks were increased along planes (100) (002). This observation proposes on doping of $\mathrm{Mn}$ into $\mathrm{ZnO}$ lattice enhances lattice crystallinity. Lattice parameters were attained from the Rietveld Refinement technique summarized in Table 1. The slight change in lattice parameters after $4 \% \mathrm{Mn}$ doping into $\mathrm{ZnO}$ lattice was noted due to $\mathrm{Mn}$ ions which have smaller ionic radii (0.66 ̊) than Zn ions ( $0.74 \AA$ ), it means a however small amount of $\mathrm{Mn}$ may change physical properties of $\mathrm{ZnO}$ material. Distortions may be developed in $\mathrm{Mn}$-doped $\mathrm{ZnO}$ lattice owing to the approximately same ionic radii which reflects the change in lattice parameters in the system [24]. The average crystallite size of pure and $\mathrm{Mn}$-doped $\mathrm{ZnO}$ samples was verified by employing the following formula [25].

$D=\frac{C \lambda}{\beta \cos \theta}$

All sharp XRD peaks were indexed by the hexagonal wurtzite phase of ZnO (JCPDS Card No. 96-900-4180) as shown in Fig. 1. It is explicitly corroborated sharp peaks exhibit the as-synthesized material is in good crystallinity state in the form of hexagon nanoparticles and $\mathrm{Mn}$-doped $\mathrm{ZnO}$ in the form of nanoflowers. In pure $\mathrm{ZnO}$ the ratio of the intensity of peak along (100), (002) and (101) planes is lower than $4 \% \mathrm{Mn}$-doped $\mathrm{ZnO}$ nanoflowers were observed nanoparticles without growth in (002) plane but which enhances for $4 \% \mathrm{Mn}$-doped

Table 1 Lattice parameters, crystalize size, lattice strain, volume of the unit cell, u parameter and c/a ratio of pure and Mn-doped ZnO nanoflowers

\begin{tabular}{|c|c|c|c|c|c|c|c|c|}
\hline \multirow[t]{2}{*}{ Sample } & \multicolumn{2}{|c|}{ Lattice parameter } & \multirow{2}{*}{$\begin{array}{l}\text { Scherrer's method } \\
D(\mathrm{~nm})\end{array}$} & \multicolumn{2}{|c|}{ W-H method } & \multirow{2}{*}{$\begin{array}{l}\text { The volume of the } \\
\text { unit cell }(\hat{A})^{3}\end{array}$} & \multirow[t]{2}{*}{ u parameter } & \multirow[t]{2}{*}{ c/a ratio } \\
\hline & $a(\mathrm{~nm})$ & $c(\mathrm{~nm})$ & & $D(\mathrm{~nm})$ & $\epsilon \times 10^{-4}$ & & & \\
\hline Pure $\mathrm{ZnO}$ & 0.3250 & 0.5206 & 27.1946 & 30.94955 & 8.29 & 47.6240 & 0.379898 & 1.6019 \\
\hline 4\% Mn:ZnO & 0.3251 & 0.5209 & 27.2145 & 33.33029 & 12.0 & 47.7114 & 0.379861 & 1.6021 \\
\hline
\end{tabular}
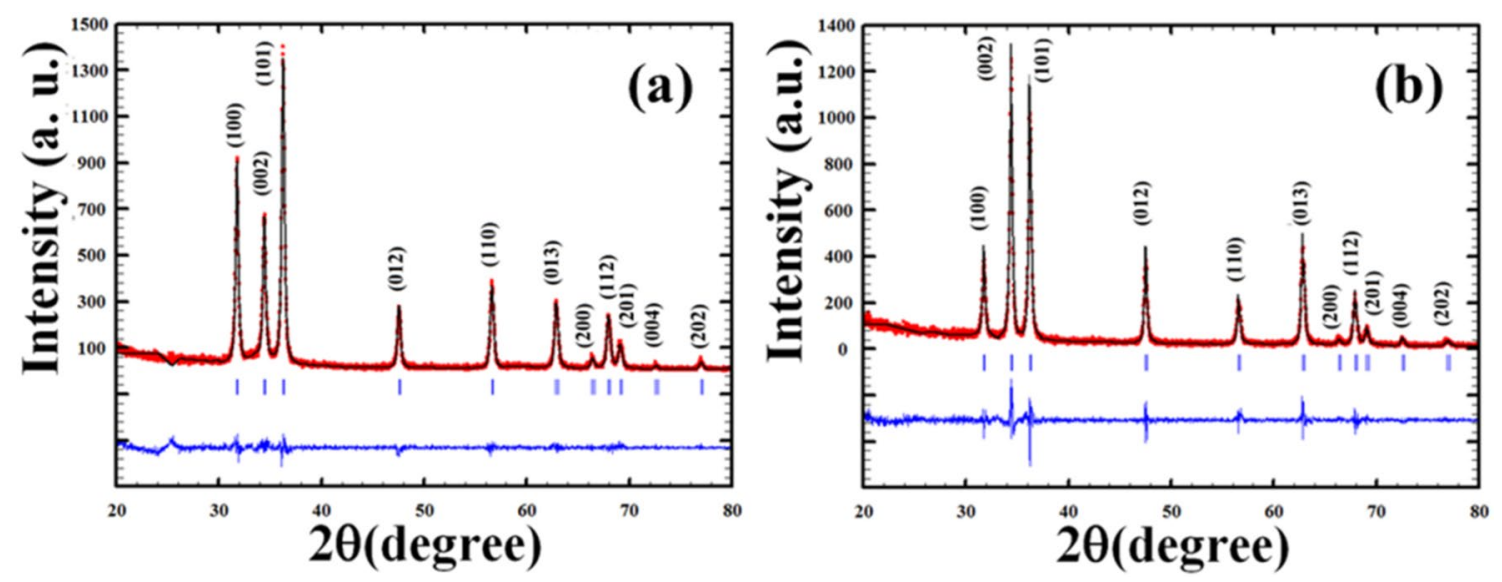

Fig. 1 Rietveld refinement of a pure $\mathrm{ZnO}$ and $\mathbf{b} 4 \%$ Mn-doped $\mathrm{ZnO}$ nanoflowers 
$\mathrm{ZnO}$ sample indicating the growth of the single crystal. It may be owing to Mn which functions as a metal catalyst and assists in the growth of nanoflowers outlines the doping effect of $\mathrm{Mn}$ into $\mathrm{ZnO}$ host lattice [26]. Using Debye-Scherrer's and Williamson-Hall methods crystalline size and effect of strain were evaluated for the pure and $\mathrm{Mn}$-doped $\mathrm{ZnO}$ nanoflowers [27]. The variation of $\beta \cos \theta$ with $4 \sin \theta$ gives the Williamson-Hall plots from which the crystallite size $D$ and lattice strain $\epsilon$ are shown in Fig. 2. W-H method results that the crystallite size enhances with the doping of $\mathrm{Mn}$ in $\mathrm{ZnO}$ lattice. This is due to the $\mathrm{Mn}$ doping which has a smaller ionic radius that causes bigger strain in the lattice. The positive strain implies an expansion in the system due to this doped system shows higher crystallite size values which were calculated by W-H method as compared to the crystallite size calculated by Scherrer's method $[27,28]$. The volume of unit cell enhances for $\mathrm{Mn}$ doping due to the positive strain that produces expansion in the lattice system. Using the following formula, the internal parameter $u$ was calculated.

$u=\frac{a^{2}}{3 c^{2}}+0.25$

where $u$ is an internal parameter, $a$ and $c$ are lattice constants. From Eq. (2) one confirms that there is a strong correlation between the $c / a$ ratio and ' $u$ '. It was acknowledged that the internal parameter ' $u$ ' decreases with increasing $c / a$ ratio in such a way that those four tetrahedral distances remain nearly constant through a distortion of tetrahedral angels due to the long-range polar interaction [29].

The aspect ratio of (100) and (002) peaks was observed from XRD patterns which exhibit a higher aspect ratio than pure for $4 \% \mathrm{Mn}$-doped $\mathrm{ZnO}$ sample.
More importantly, the hydrothermal method is a successful and general procedure to control the aspect ratio and adjust the surface defects. The high aspect ratio and Crystallinity of $4 \% \mathrm{Mn}$-doped $\mathrm{ZnO}$ nanoflowers are playing major and responsible role for the higher photocatalytic activity under solar light irradiation.

\subsection{X-ray photoelectron spectroscopy}

For the demonstration of the photocatalytic mechanism that involves $\mathrm{Mn}^{2+}$ doping and vacancy defects on the nanoflowers surface, the surface element compositions and chemical phases of both pure and $4 \% \mathrm{Mn}$-doped $\mathrm{ZnO}$ samples using XPS analysis outlined. From XPS analysis, the presence of $\mathrm{Zn}$ and $\mathrm{O}$ elements are observed in both samples as shown in Fig. 3 , but the existence of $\mathrm{Mn}$ is only in the $\mathrm{Mn}$-doped $\mathrm{ZnO}$ sample. For the conformation of chemical phases of each element, high-resolution XPS spectra for $\mathrm{Mn} 2 p, \mathrm{Zn} 2 p$, and $\mathrm{O} 1 s$ states are depicted in Fig. 4a-d. For a $4 \% \mathrm{Mn}$-doped $\mathrm{ZnO}$ sample, double peaks at 641 and $651 \mathrm{eV}$ corresponded to the $\mathrm{Mn}^{2+} 2 p$ level of $\mathrm{P}_{3 / 2}$ and $\mathrm{P}_{1 / 2}$, respectively, indicating that the chemical state of $\mathrm{Mn}$ has existed as $\mathrm{Mn}^{2+}$ in $4 \% \mathrm{Mn}$-doped $\mathrm{ZnO}$ samples. It was explicitly confirmed that the $\mathrm{Mn}^{2+}$ doped $\mathrm{ZnO}$ sample was successfully prepared. In Fig. $4 \mathrm{~b}$, the peaks related to $\mathrm{Zn} 2 p$ for both samples are observed and there are two symmetric peaks present in the $Z n 2 p$ region. The peak centered at $1022 \mathrm{eV}$ corresponds to $\mathrm{Zn} 2 p_{3 / 2}$ and another one centered at 1045 is assigned to $\mathrm{Zn} 2 p_{1 / 2}$, indicating a normal state of $\mathrm{Zn}^{2+}$ in the both samples. From Fig. $4 \mathrm{c}, \mathrm{d}$ it is clearly seen that the high-resolution $O 1 s$ spectra for pure and $\mathrm{Mn}$-doped $\mathrm{ZnO}$ samples respectively. It reflects the asymmetric $O 1 s$ core spectrum deconvoluted with one and three peaks respectively. In the case of pure $\mathrm{ZnO}$ sample, only one peak at $531.5 \mathrm{eV}$ which was assigned to
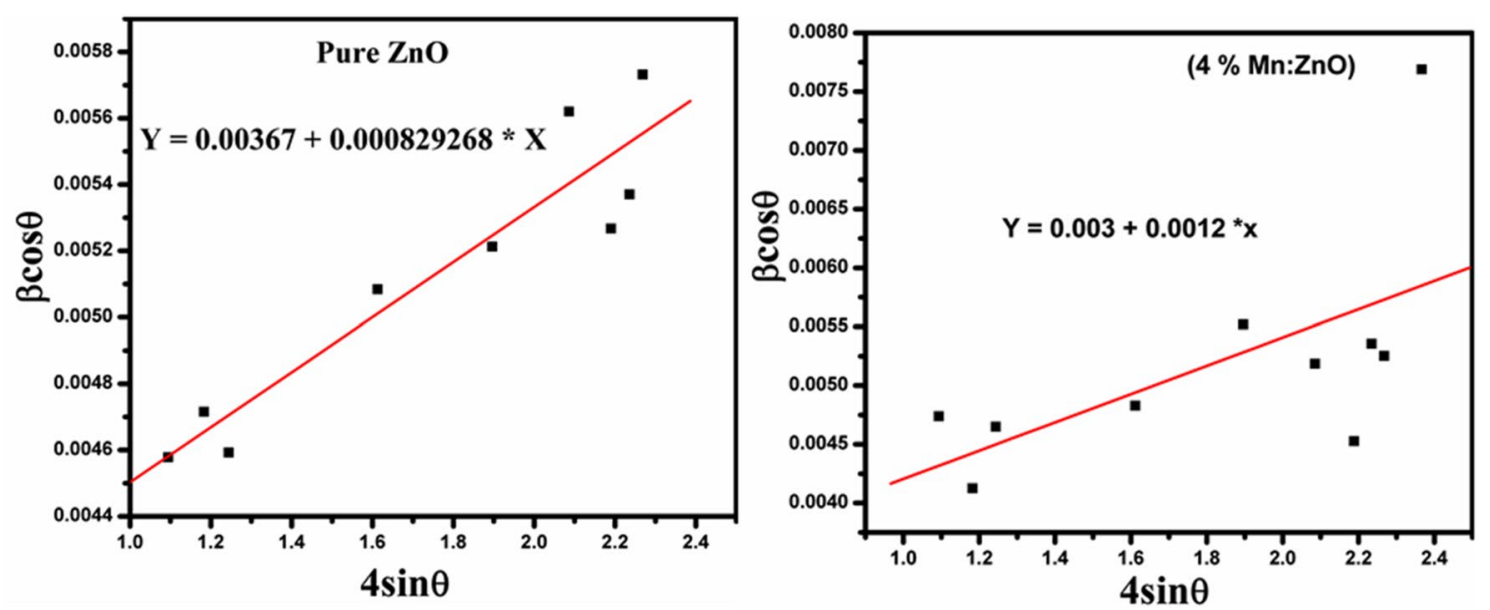

Fig. 2 Plots of $\mathrm{W}-\mathrm{H}$ method for $4 \sin \theta$ versus $\beta \cos \theta$ of Pure and $4 \% \mathrm{Mn}$, doped $\mathrm{ZnO}$ nanoflowers 


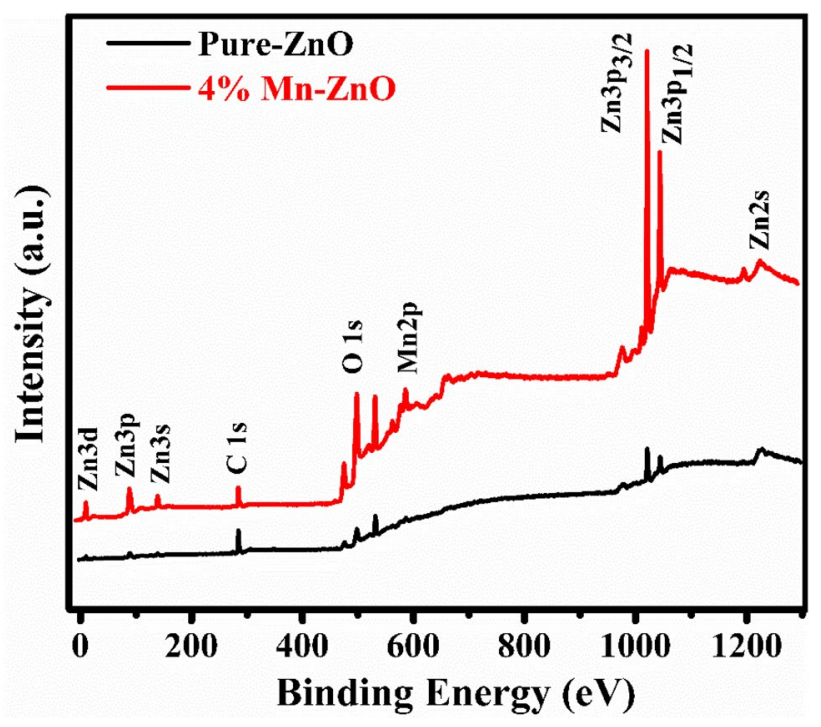

Fig. 3 Full scan XPS spectra of pure and Mn-doped $\mathrm{ZnO}$ nanoflowers
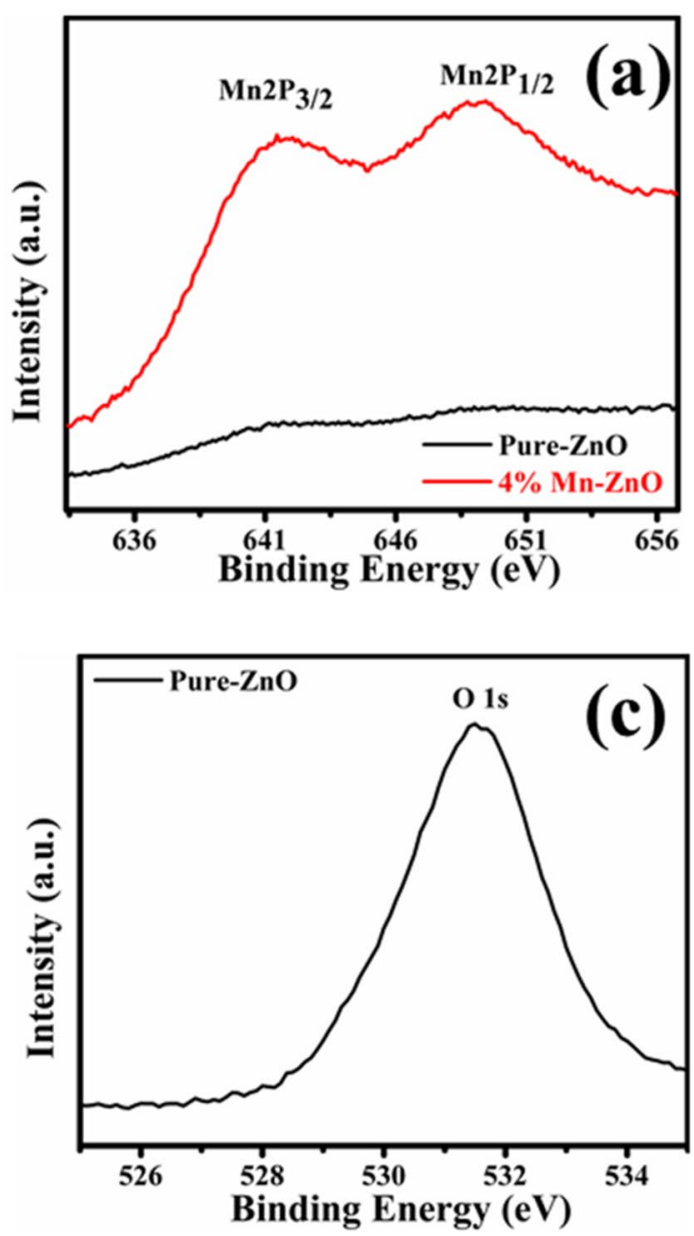

$\mathrm{O}^{2-}$ ions in the oxygen-deficient regions and is related to oxygen vacancies [30]. In the $\mathrm{Mn}$-doped $\mathrm{ZnO}$ sample, the first peak centered at $529.9 \mathrm{eV}$ corresponds to the $\mathrm{O}^{2-}$ ions in the wurtzite structure $(\mathrm{O}-\mathrm{Zn})$. While the medium peak at $531.5 \mathrm{eV}$ is assigned to $\mathrm{O}^{2-}$ ions in the oxygen-deficient regions. The FWHM of O $1 \mathrm{~s}$ peak for pure $\mathrm{ZnO}$ was 2.70 and for $4 \% \mathrm{Mn}$-doped $\mathrm{ZnO}$, it was decreased up to 2.40 . It was exhibited that the $\mathrm{O} 1 \mathrm{~s}$ peaks for $\mathrm{Mn}$-doped $\mathrm{ZnO}$ nanoflowers become slightly smaller with increasing of surface defects or large surface area. It was fitted by Gaussian distribution with two peaks which corresponded to $\mathrm{O}-\mathrm{Zn}$ and $\mathrm{O}-\mathrm{H}$ respectively. The medium binding energy component, centered at $531.5 \mathrm{eV}$, was due to the variations in the concentration of oxygen vacancies; therefore, the intensity change is due to the variations in the concentration of surface oxygen vacancies. The intensity of this peak increases after substituting $\mathrm{Mn}^{2+}$ in $\mathrm{ZnO}$ [31]. Peak intensity was found to increase for $4 \% \mathrm{Mn}$-doped $\mathrm{ZnO}$ sample exhibits diffusion of atoms towards the surface. The increase in surface defects and variation in surface oxygen vacancies are helpful to increase the photocatalytic activity of
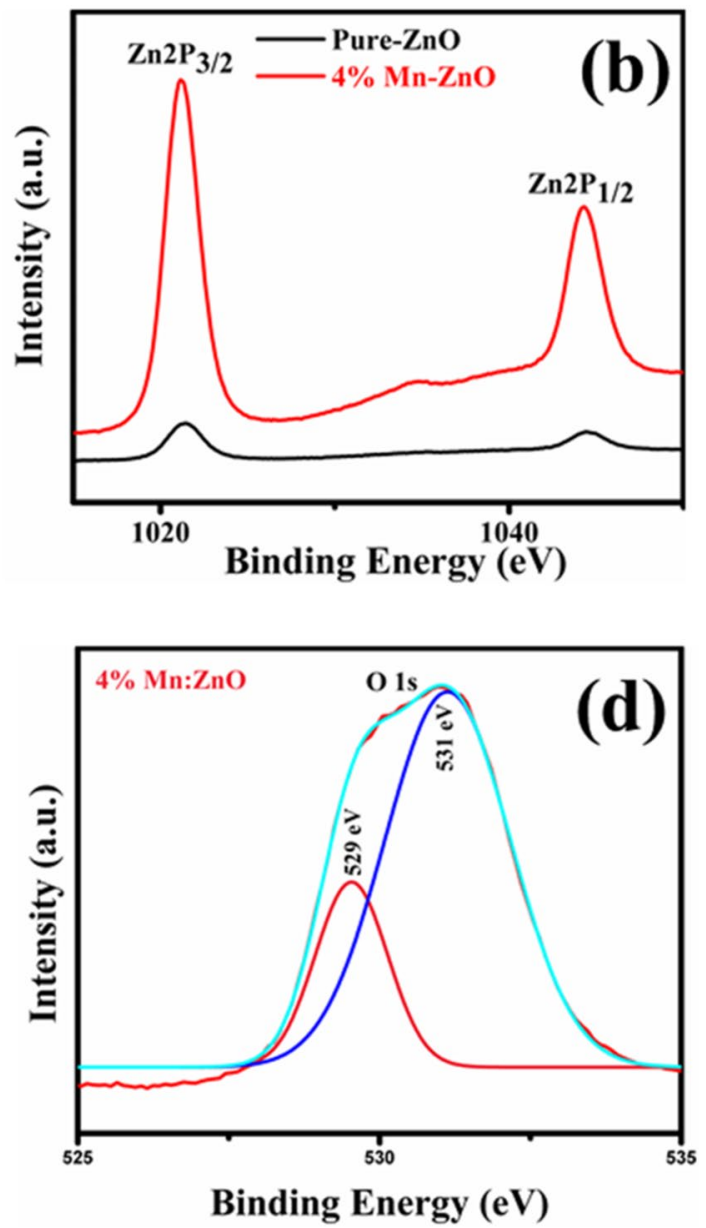

Fig. 4 a Mn2p spectra, b Zn2p, c O 1 s of pure $\mathrm{ZnO}$ and d O 1 s of $4 \% \mathrm{Mn}$-doped $\mathrm{ZnO}$ nanoflowers 
photocatalyst. Surface defects play a very important role in the photocatalytic activity hence the $4 \% \mathrm{Mn}$-doped $\mathrm{ZnO}$ nanoflowers with high aspect ratio and surface defects is responsible for the higher photocatalytic activity under visible light irradiation. In reported literature, XPS results show that the formation of oxygen vacancies after annealing treatment while in our study $\mathrm{Mn}$-doped $\mathrm{ZnO}$ sample exhibits the formation of oxygen vacancies at room temperature which indicates that $\mathrm{Mn}$ is responsible for the formation of oxygen vacancies [32].

\subsection{Scanning electron microscopy}

Morphological variations for $\mathrm{Mn}$-doped $\mathrm{ZnO}$ nanoflowers were observed using the SEM technique. Figure 5 shows the images of pure and $\mathrm{Mn}$-doped $\mathrm{ZnO}$ nanoflowers consisting of nanorods, which were hydrothermally grown on the glass substrates without the $\mathrm{ZnO}$ seed layer. In pure $\mathrm{ZnO}$ sample, hexagonal nanoparticles with a flat surface were observed but for $4 \% \mathrm{Mn}$-doped $\mathrm{ZnO}$ sample, nanoflowers were formed. It was outlined from the figure the small-sized nanoflowers with a large number of branches formed in the $\mathrm{Mn}$-doped $\mathrm{ZnO}$ sample. Based on the literature of previously reported work and the results of the present work, we have observed that the formation of nanoflowers for a $4 \% \mathrm{Mn}$ doped $\mathrm{ZnO}$ sample could be achieved in the presence of $\mathrm{Mn}$ metal catalyst. In the present work, the formation of Mndoped $\mathrm{ZnO}$ nanoflowers obtained from anisotropic growth under the effects of hydrothermal conditions. Variations in the ionic strength of the hydrothermal solution for Mn may contribute to the formation of nanoflowers. Thus Mn plays a vital role in the formation of the Mn-doped $\mathrm{ZnO}$ nanoflowers. In a hydrothermal process, anisotropically grown single crystal along the c-axis to form hexagonal rod which depends on the concentration of dopant $\mathrm{Mn}$, Zinc solution and HMTA which were used in the synthesis method. However, when the concentration of $\mathrm{ZnO}$ and $\mathrm{Mn}$ nuclei is more, then they easily aggregate together to decrease surface energy. Every nucleus in the aggregate grows anisotropically along the c-axis, forms an $\mathrm{Mn}$-doped $\mathrm{ZnO}$ nanoflowers [33]. The grain size of the pure $\mathrm{ZnO}$ sample was calculated and found to be $50 \mathrm{~nm}$. The length and diameter of Mn-doped $\mathrm{ZnO}$ nanoflowers were calculated by image-j software which was found to be $652 \mathrm{~nm}$ and $94 \mathrm{~nm}$ respectively.

\subsection{UV-Vis spectroscopy}

To determine the optical properties of the pure and $\mathrm{Mn}$ doped $\mathrm{ZnO}$, the absorbance spectra were used. UV-Vis absorption technique was used to examine the change in the energy band structure of $\mathrm{ZnO}$ on the substitution of $\mathrm{Mn}$. The room temperature UV-Vis absorption spectra of pure and $4 \% \mathrm{Mn}$-doped $\mathrm{ZnO}$ nanoflowers in the wavelength range 350-900 nm was investigated and shown in Fig. 6. The sharp absorption edge observed around $380 \mathrm{~nm}$ for both samples. The absorption coefficient ( $a$ ) was intervened, which depends on the film thickness and absorption, by the following equation [34]:

$\alpha=2.303 \mathrm{~A} / \mathrm{t}$

where $A$ is the absorbance and $t$ is the thickness of the sample. The energy band gap of the pure and $\mathrm{Mn}$-doped $\mathrm{ZnO}$ was calculated by the following Tauc equation [34]:

$\alpha h v=A(h v-E g)^{1 / 2}$

where $A$ is the constant, $E g$ is the energy gap, $v$ is the frequency of the incident radiation and $h$ is Planck's constant.

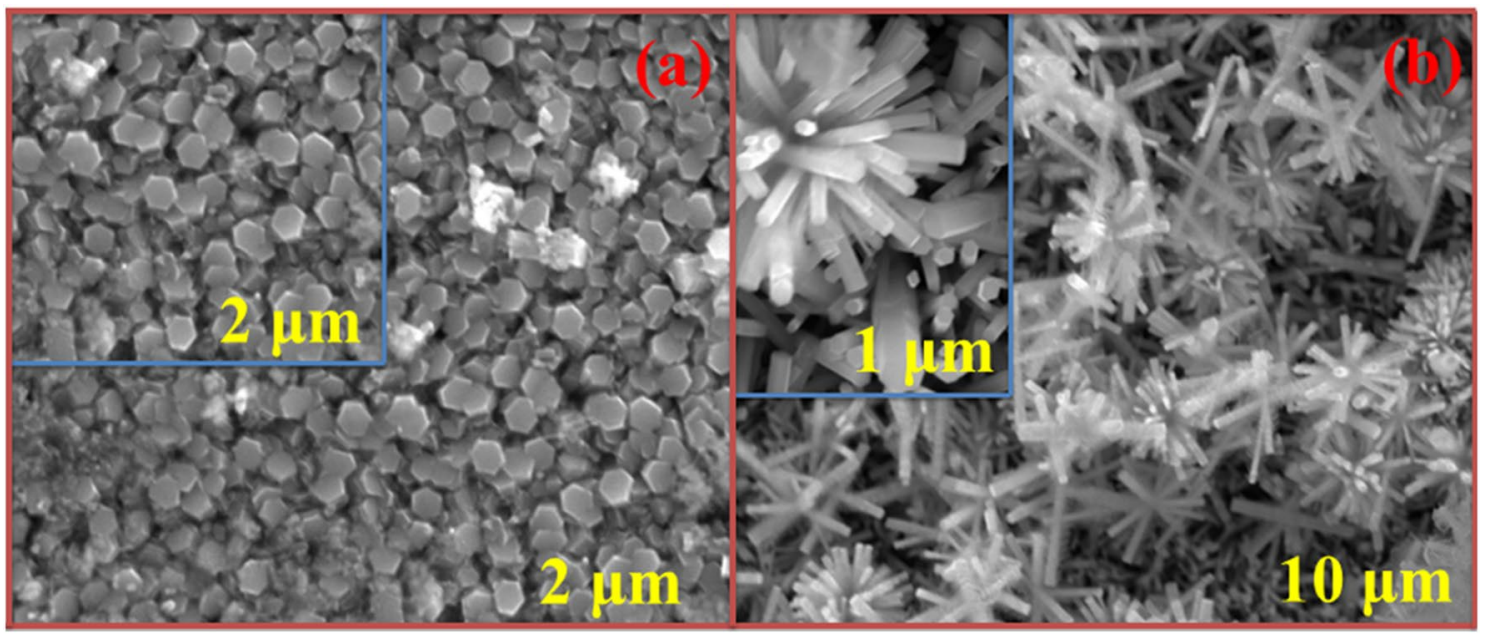

Fig. 5 SEM images of a pure, b $4 \% \mathrm{Mn}$-doped $\mathrm{ZnO}$ nanoflowers

SN Applied Sciences 


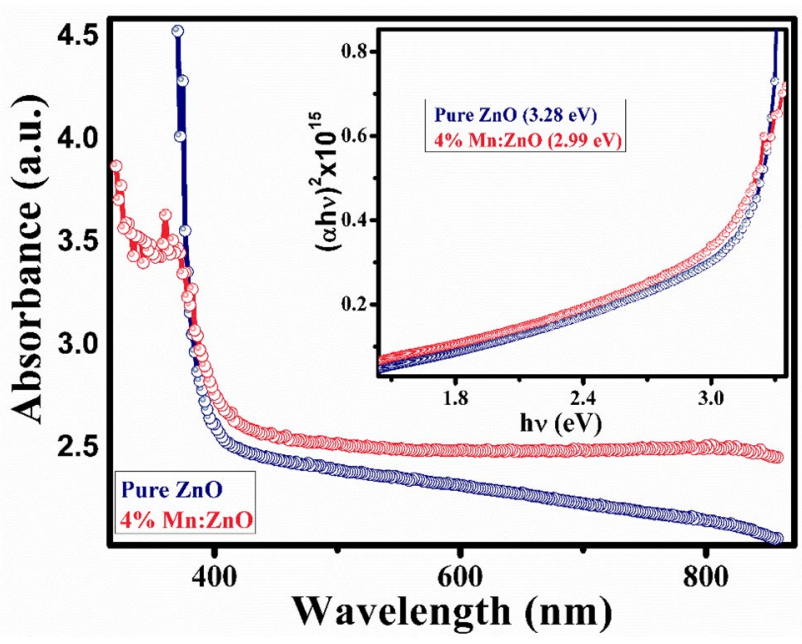

Fig. 6 UV-Vis absorbance spectra and the band gap of Pure and $4 \% \mathrm{Mn}$-doped $\mathrm{ZnO}$ nanoflowers

$\mathrm{ZnO}$ is a direct band gap semiconductor; the optical band gap was investigated by the plot of $(\alpha h v)^{2}$ versus hv. The band gap of $4 \% \mathrm{Mn}$-doped $\mathrm{ZnO}$ is small as compared to the band gap of Pure $\mathrm{ZnO}$ which outlines the redshift. This is due to the quantum confinement of electron in one dimensional $\mathrm{Mn}$-doped $\mathrm{ZnO}$ nanoflowers [28]. The efficiency of photocatalysis depends upon the harvested region of the solar spectrum by $\mathrm{ZnO}$ nanomaterials and the rate of electron-hole pair generation. Due to the wide band gap of $\mathrm{ZnO}$ can harvest only in the UV region. For the enhancement of photocatalytic efficiency, it is essential to absorb a larger spectrum of sunlight so that more electron-hole pairs can be generated [35, 36]. For this reason, a narrow band gap is required for the enhancement of photocatalytic efficiency. In our investigation, 4\% Mn-doped $\mathrm{ZnO}$ nanoflowers have a narrow energy band gap which plays a vital role in photocatalytic activity. The refractive index is one of the most important factors for designing the nanostructured thin film material which enhances photocatalytic efficiency and acts as the function of wavelength to predict the photoelectric behavior. The refractive index ( $n$ ) of pure and $\mathrm{Mn}$-doped $\mathrm{ZnO}$ nanoflower was estimated by using Herve-Vandamme equation [37, 38].

$(n)=\sqrt{1+\left(\frac{A}{E_{g}+B}\right)^{2}}$

where $A=13.6 \mathrm{eV}$ and $B=3.4 \mathrm{eV}$ are the constants, and $E_{g}$ is the optical energy band gap which was obtained from Tauc's equation, and it was explicitly confirmed the relation was well suited for optical property studies. Standard optical Refractive index value is for $\mathrm{ZnO}$ nanomaterial has $n=2.0034$ reported in the literature but in our as-prepared sample for pure $\mathrm{ZnO} n=2.2682$ and for $\mathrm{Mn}$-doped $\mathrm{ZnO}$ nanoflowers $n=2.3515$ which demonstrates enhancement in refractive index values after owing to the creation of oxygen vacancy.

\subsection{Atomic force microscopy}

Analysis of 3D surface topography of pure $\mathrm{ZnO}$ and $4 \%$ $\mathrm{Mn}$-doped $\mathrm{ZnO}$ nanoflowers from atomic force microscopy was examined and found in good agreement with structural and morphological parameters. Root mean square (RMS) roughness of Pure $\mathrm{ZnO}$ nanoparticles was obtained to be $260 \mathrm{~nm}$ whereas for $\mathrm{Mn}$-doped $\mathrm{ZnO}$ nanoflowers it was reduced to $118 \mathrm{~nm}$. Pure $\mathrm{ZnO}$ has higher roughness due to non-uniform deposition on a glass substrate $[18,39]$ and its thickness was also larger than $\mathrm{Mn}$-doped $\mathrm{ZnO}$ nanoflowers while $\mathrm{Mn}$-doped $\mathrm{ZnO}$ nanoflower thin film deposited uniformly and growth of nanoflowers was also uniformly as depicted in Fig. 7. From histogram as depicted in Fig. $7 \mathrm{c}$ is the double exponential distribution which is symmetric distribution but as compared to normal, which has a stronger peak with rapid decay and heavier tails. In Pure ZnO nanoparticle sample, skewness was calculated by theoretically we would expect near zero but experimentally it was found to be -0.3 and kurtosis was 5.77 . From the histogram, as shown in Fig. $7 d$ is the normal distribution which reveals symmetric distribution with well-behaved tails. Mn-doped $\mathrm{ZnO}$ nanoflowers have a skewness of -0.08 which means left-skewed distributions and its Kurtosis of 2.80 which was closer to the expected value of $3[40,41]$. It outlines that, this sample verifies the symmetry belonging to the morphology. From the analysis of roughness, skewness, and Kurtosis it may conclude that the Mn-doped $\mathrm{ZnO}$ nanoflower sample is the best candidate for photocatalytic activity application.

\subsection{Photocatalytic activity}

The photodegradation efficiency of photocatalytic reactions is much dependent on the specific surface area of the photocatalysis. Photocatalytic activity of the pure and Mndoped $\mathrm{ZnO}$ was intervened by monitoring the degradation of Methylene Blue dye solution under visible irradiation in the presence of the catalyst. Absorbance spectra of the dye solution were measured at intervals of 20 min under visible irradiation for pure and $4 \% \mathrm{Mn}$-doped $\mathrm{ZnO}$ thin films $(1 \times$ $1 \mathrm{~cm})^{2}$ as shown in Fig. $8 \mathrm{a}$, b respectively. The intensity of the characteristic absorption peak of MB was around $642 \mathrm{~nm}$ decreased with an increase in irradiation time. For the pure $\mathrm{ZnO}$ photocatalyst, the peak was almost disappeared up to 0.08 (a. u.) after $2.6 \mathrm{~h}$ irradiation while for the $4 \% \mathrm{Mn}$-doped $\mathrm{ZnO}$ nanoflowers, this was about $2 \mathrm{~h}$. The photocatalytic degradation efficiency of the pure and $4 \% \mathrm{Mn}$-doped $\mathrm{ZnO}$ nanoflowers were verified and found which results for pure 

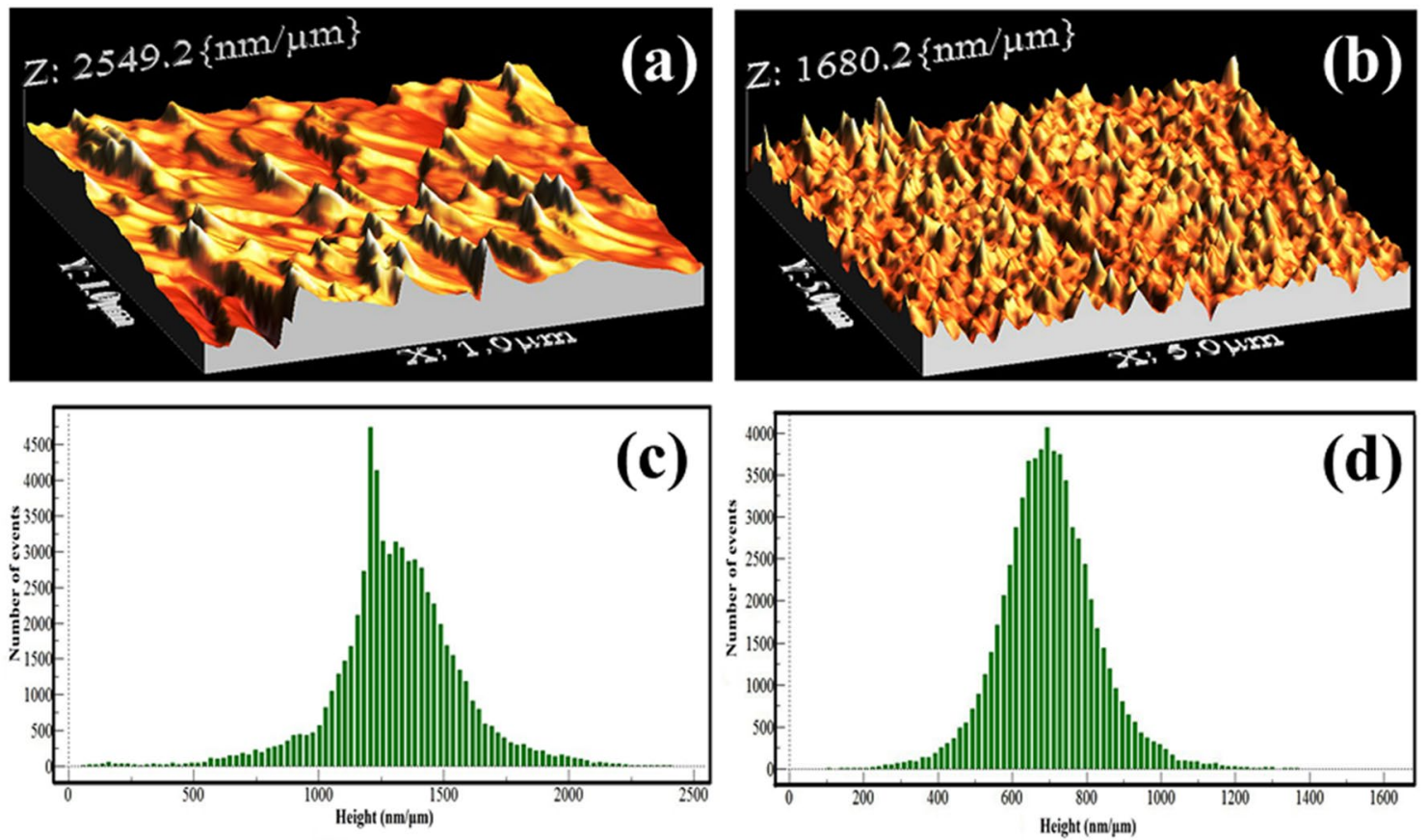

Fig. 7 AFM images of a pure $\mathrm{ZnO}$, b $\mathrm{Mn}$-doped $\mathrm{ZnO}$, and histogram of $\mathbf{c}$ pure $\mathrm{ZnO}$, $\mathbf{d}$ Mn-doped $\mathrm{ZnO}$ nanoflowers

and $4 \% \mathrm{Mn}$-doped $\mathrm{ZnO}$ were $65 \%$ and $81 \%$, respectively which confirms that $\mathrm{Mn}$-doped $\mathrm{ZnO}$ nanoflowers are more efficient in photocatalysis. Kinetic studies were performed for pure and 4\% $\mathrm{Mn}$-doped $\mathrm{ZnO}$ samples these results are depicted in Fig. 9a, b. It is noted that the photodegradation of methylene blue follows pseudo-first-order kinetics, which is given below [12],

$\log \frac{C_{0}}{C_{t}}=k t$ where $C_{0}$ and $C_{t}$ are the concentrations of methylene blue at time $t=0$ and time $t=120 \mathrm{~min}$, respectively, $k$ is the pseudo-first-order rate constant. The rate constant $(k)$ was verified using the slope of the plot of $\log \frac{C_{0}}{C_{t}}$ versus irradiation time. The values of rate constant $(k)$ for pure and $4 \%$ $\mathrm{Mn}: \mathrm{ZnO}$ are 0.2209 and 0.3457 respectively which outline that 4\% Mn-doped $\mathrm{ZnO}$ sample has a higher rate constant than pure $\mathrm{ZnO}$ sample, it may be the formation of defects. The enhancement in degradation efficiency and rate constant for 4\% Mn-doped $\mathrm{ZnO}$ sample can be attributed to
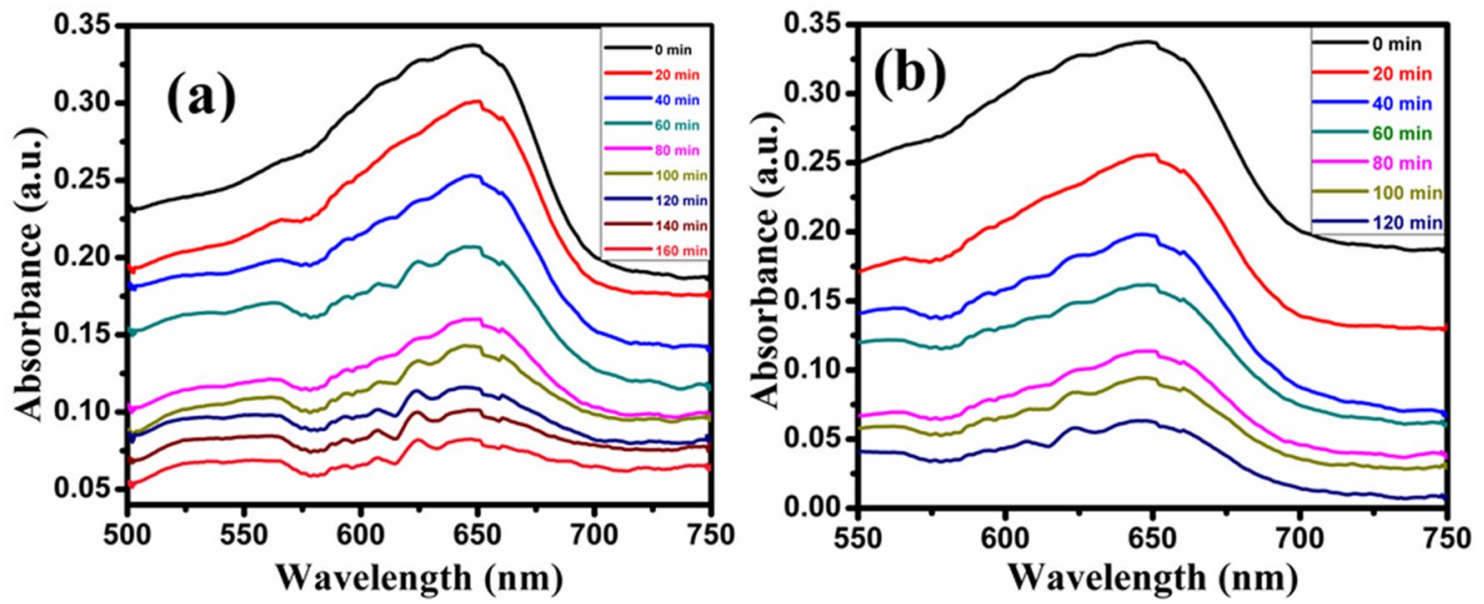

Fig. 8 Time-dependent absorption spectra of MB solutions in the presence of a pure $\mathrm{ZnO}$ and $\mathbf{b} 4 \% \mathrm{Mn}$-doped $\mathrm{ZnO}$ nanoflowers 

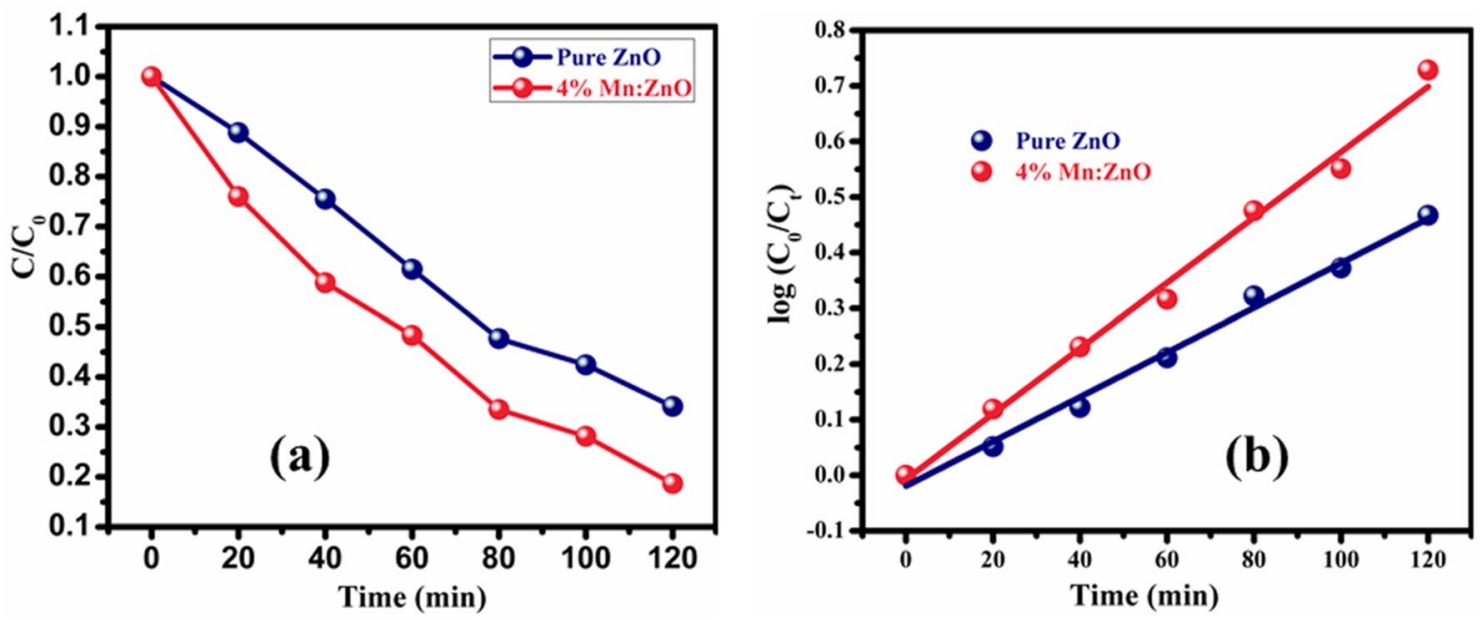

Fig. 9 Plots of $\mathbf{a} C / C_{0}$ and $\mathbf{b} \log \left(C_{0} / C_{t}\right)$ for Pure and $\mathrm{Mn}$-doped $\mathrm{ZnO}$ nanoflowers

the high surface area, higher crystallinity, reduced rate of electron-hole recombination and oxygen vacancies as compared to pure $\mathrm{ZnO}$ sample. It is noticed that $\mathrm{ZnO}$ photocatalysis is based on the generation of an electron-hole pair in light irradiation. It was corroborated that the photoinduced electron-hole easily recombined in the photocatalytic activity. Therefore, it is important to reduce the surface recombination of electrons and holes. Oxygen vacancies can act as electron acceptors during the photocatalytic reaction and thus reduce the recombination rate. Therefore, oxygen vacancies can play a vital role to enhance the photocatalytic properties of photocatalyst [42]. During the photocatalytic performance, vacancies and defects create the trap centers of photogenerated electrons hence the electron-hole recombination is effectively inhibited. Oxygen vacancies also act as charge carrier traps as well as adsorption sites where the charge transfers to adsorbed species, which can prevent electron-hole recombination. To evaluate the reusability of pure and $\mathrm{Mn}$-doped $\mathrm{ZnO}$ samples photocatalyst, the degradation efficiency of $\mathrm{MB}$ under visible irradiation in four cycles as shown in Fig. 10. Over the four cycles degradation efficiency remains the same which indicates the stability of prepared samples. Nur Ajrina et al. reported that photodegradation efficiency for $7 \% \mathrm{Mn}$-doped $\mathrm{ZnO}$ nanorods was $76.75 \%$ under UV irradiation while in our case it was $82 \%$ for $4 \% \mathrm{Mn}$-doped $\mathrm{ZnO}$ nanoflowers under visible irradiation [43]. This clearly verifies that the $4 \% \mathrm{Mn}$-doped $\mathrm{ZnO}$ nanoflowers on glass substrate are reusable and more stable. Therefore $4 \% \mathrm{Mn}$-doped $\mathrm{ZnO}$ sample is a promising candidature for photocatalytic degradation under visible light irradiation and functions effectively (Table 2).

Fluorescence spectroscopy and BET surface defect study results were supplied in ESI [12, 44-46].

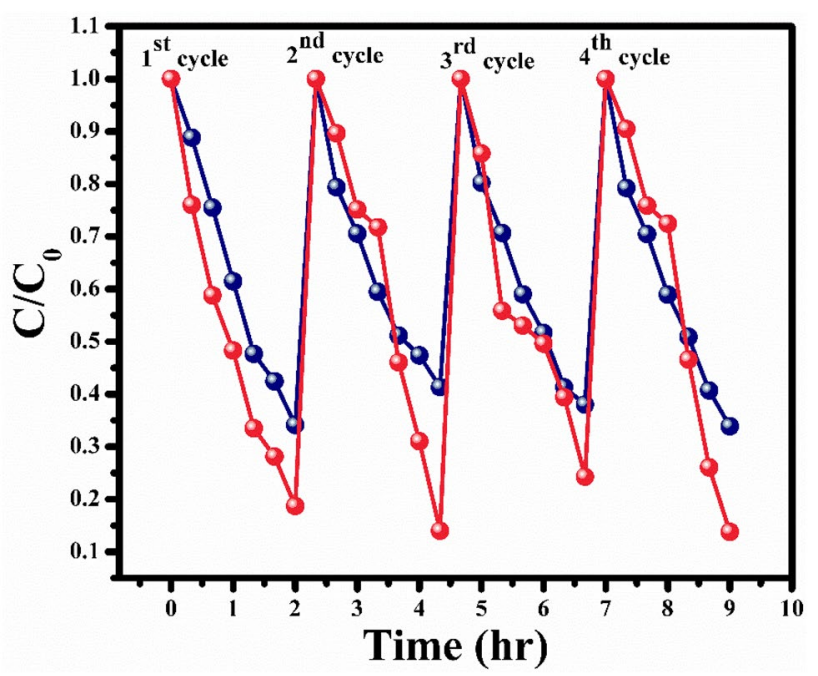

Fig. 10 Variation of the relative concentration of $\mathrm{MB}$ dye solution under visible irradiation in the presence of pure and $4 \% \mathrm{Mn}$-doped $\mathrm{ZnO}$ nanoflowers over 4 cycles

\section{Conclusions}

Pure and $\mathrm{Mn}$-doped $\mathrm{ZnO}$ nanoflowers were successfully synthesized by the hydrothermal method and also the photocatalytic activity performance intervened in the as-prepared samples successfully. It is explicitly concluded that the obtained $4 \% \mathrm{Mn}$-doped $\mathrm{ZnO}$ nanocatalyst exhibits an excellent candidate with high photocatalytic performance for the degradation of the methylene blue dye (MB) than pure $\mathrm{ZnO}$ catalyst under the solar light irradiation. The produced pure and $\mathrm{Mn}$-doped $\mathrm{ZnO}$ catalyst samples were found to depend on the synthesis parameters in their morphology, crystallite size, surface 
Table 2 Comparative table for MB dye degradation in sunlight/visible light

\begin{tabular}{llllll}
\hline Sr. No. & Photo catalyst & Dye concentration & Time $(\mathrm{h})$ & $\begin{array}{l}\text { Photo degrada- } \\
\text { tion efficiency (\%) }\end{array}$ & Ref. nos. \\
\hline 1 & $\mathrm{a}-\mathrm{Bi}_{2} \mathrm{O}_{3}$ & $2 \times 10^{-5} \mathrm{M}$ & 6 & 30 & {$[47]$} \\
2 & $\mathrm{a}-\mathrm{Fe}_{2} \mathrm{O}_{3}$ & $20 \mathrm{mg} / \mathrm{L}$ & 8.3 & 51 & {$[48]$} \\
3 & $\mathrm{CuO}$ & $3 \times 10^{-5} \mathrm{M}$ & 6 & 43 & {$[49]$} \\
4 & $\mathrm{ZnS}: \mathrm{CdS}(\mathrm{wt} \% 50: 50)$ & $10 \mathrm{mg} / \mathrm{L}$ & 6 & 65 & {$[50]$} \\
5 & Pure $\mathrm{ZnO}$ & $5 \mathrm{mg} / \mathrm{L}$ & 2.6 & 65 & Present work \\
6 & $4 \% \mathrm{Mn}: \mathrm{ZnO}$ & $5 \mathrm{mg} / \mathrm{L}$ & 2 & 81 & Present work \\
\hline
\end{tabular}

area and subsequently photocatalytic activity. The photocatalytic performance of $4 \% \mathrm{Mn}$-doped $\mathrm{ZnO}$ nanoflowers has a faster rate constant than pure $\mathrm{ZnO}$ which indicates $\mathrm{Mn}$ is promising candidature for improving the photocatalysis. XPS results show the incorporation of $\mathrm{Mn}$ into $\mathrm{ZnO}$ lattice. The formation of oxygen vacancies and defects which are important parameters for the improvement in photocatalytic activity. The presence of green emission in fluorescence spectra signifies that more defects are present in 4\% $\mathrm{Mn}$-doped $\mathrm{ZnO}$ nanoflowers. All characterizations and evaluation tools support that a $4 \% \mathrm{Mn}$-doped $\mathrm{ZnO}$ sample under solar light irradiation is an excellent catalyst and financially affordable.

Acknowledgements Authors are grateful for financial support through the DST-SERB Project No. SERB, SB/S2/CMP-097/2013, New Delhi, India and Prof. S.S. Shah for his scientific discussion and encouragement.

\section{Compliance with ethical standards}

Conflict of interest The authors declare that they have no known competing financial interests or personal relationships that could have appeared to influence the work reported in this paper.

\section{References}

1. Ganesh RS, Sharma SK, Durgadevi E, Navaneethan M, Ponnusamy S, Muthamizhchelvan C, Hayakawa Y, Kim DY (2017) Growth, microstructure, structural and optical properties of PVP-capped CdS nanoflowers for efficient photocatalytic activity of Rhodamine B. Mater Res Bull 94:190-198

2. Ganesh RS, Durgadevi E, Navaneethan M, Sharma SK, Binitha HS, Ponnusamy S, Muthamizhchelvan C, Hayakawa Y (2017) Visible light induced photocatalytic degradation of methylene blue and rhodamine B from the catalyst of CdS nanowire. Chem Phys Lett 684:126-134

3. Zhang Y, Ram MK, Stefanakos EK, Goswami DY (2012) Synthesis, characterization, and applications of $\mathrm{ZnO}$ nanowires. J Nanomater 2012:22

4. Sabir S, Arshad M, Chaudhari SK (2014) Zinc oxide nanoparticles for revolutionizing agriculture: synthesis and applications. Sci World J 2014:8

5. Liu B, Zeng HC (2003) Hydrothermal synthesis of $\mathrm{ZnO}$ nanorods in the diameter regime of $50 \mathrm{~nm}$. J Am Chem Soc 125:4430-4431
6. Ganesh RS, Sharma SK, Durgadevi E, Navaneethan M, Binitha HS, Ponnusamy S, Muthamizhchelvan C, Hayakawa Y, Kim DY (2017) Surfactant free synthesis of CdS nanospheres, microstructural analysis, chemical bonding, optical properties and photocatalytic activities. Superlattices Microstruct 104:247-257

7. Chen X, Wu Z, Liu D, Gao Z (2017) Preparation of ZnO photocatalyst for the efficient and rapid photocatalytic degradation of azo dyes. Nanoscale Res Lett 12:143

8. Saravanan R, Gupta VK, Narayanan V, Stephen A (2014) Visible light degradation of textile effluent using novel catalyst $\mathrm{ZnO} / \mathrm{Y}$ $\mathrm{Mn}_{2} \mathrm{O}_{3}$. J Taiwan Inst Chem Eng 45:1910-1917

9. Saravanan R, Gupta VK, Narayanan V, Stephen A (2013) Comparative study on photocatalytic activity of $\mathrm{ZnO}$ prepared by different methods. J Mol Liq 181:133-141

10. Qin J, Yang C, Cao M, Zhang X, Rajendran S, Limpanart S, Ma M, Liu R (2017) Two-dimensional porous sheet-like carbon-doped $\mathrm{ZnO} / \mathrm{g}-\mathrm{C}_{3} \mathrm{~N}_{4}$ nanocomposite with high visible-light photocatalytic performance. Mater Lett 189:156-159

11. Gnanasekaran L, Hemamalini R, Saravanan R, Ravichandran $K$, Gracia F, Agarwal S, Gupta VK (2017) Synthesis and characterization of metal oxides $\left(\mathrm{CeO}_{2}, \mathrm{CuO}, \mathrm{NiO}, \mathrm{Mn}_{3} \mathrm{O}_{4}, \mathrm{SnO}_{2}\right.$ and $\left.\mathrm{ZnO}\right)$ nanoparticles as photo catalysts for degradation of textile dyes. J Photochem Photobiol B 173:43-49

12. Raskar ND, Dake DV, Mane VA, Stathatos E, Deshpande U, Dole B (2019) One step synthesis of vertically grown Mn-doped ZnO nanorods for photocatalytic application. J Mater Sci: Mater Electron 30:10886-10899

13. Joicy S, Saravanan R, Prabhu D, Ponpandian N, Thangadurai P (2014) $\mathrm{Mn}^{2+}$ ion influenced optical and photocatalytic behaviour of Mn-ZnS quantum dots prepared by a microwave assisted technique. RSC Advances 4:44592-44599

14. Gnanasekaran $L$, Hemamalini R, Saravanan $R$, Ravichandran $K$, Gracia F, Gupta VK (2016) Intermediate state created by dopant ions ( $\mathrm{Mn}, \mathrm{Co}$ and $\mathrm{Zr}$ ) into $\mathrm{TiO}_{2}$ nanoparticles for degradation of dyes under visible light. J Mol Liq 223:652-659

15. Sharma HK, Archana R, Sankar Ganesh R, Singh BP, Ponnusamy S, Hayakawa Y, Muthamizhchelvan C, Raji P, Kim DY, Sharma SK (2019) Substitution of $\mathrm{Al}^{3+}$ to $\mathrm{Zn}^{2+}$ sites of $\mathrm{ZnO}$ enhanced the photocatalytic degradation of methylene blue under irradiation of visible light. Solid State Sci 94:45-53

16. Sankar S, Sharma SK, An N, Lee H, Kim DY, Im YB, Cho YD, Ganesh RS, Ponnusamy S, Raji P, Purohit LP (2016) Photocatalytic properties of $\mathrm{Mn}$-doped $\mathrm{NiO}$ spherical nanoparticles synthesized from sol-gel method. Optik 127:10727-10734

17. Cho S, Kim S, Jang J-W, Jung S-H, Oh E, Lee BR, Lee K-H (2009) Large-scale fabrication of sub-20-nm-diameter $\mathrm{ZnO}$ nanorod arrays at room temperature and their photocatalytic activity. J Phys Chem C 113:10452-10458

18. Khawal HA, Dole BN (2017) A study of the $160 \mathrm{MeV} \mathrm{Ni}^{7+}$ swift heavy ion irradiation effect of defect creation and shifting of the phonon modes on $\mathrm{Mn}_{x} \mathrm{Zn}_{1-x} \mathrm{O}$ thin films. RSC Adv 7:34736-34745 
19. Nimbalkar AR, Patil MG (2017) Synthesis of ZnO thin film by sol-gel spin coating technique for $\mathrm{H} 2 \mathrm{~S}$ gas sensing application. Physica B 527:7-15

20. Poornajar M, Marashi P, Haghshenas Fatmehsari D, Kolahdouz Esfahani M (2016) Synthesis of ZnO nanorods via chemical bath deposition method: the effects of physicochemical factors. Ceram Int 42:173-184

21. Zhuo C, Shum K, Salagaj T, Wei Z, Strobl K (2010) ZnO thin films synthesized by chemical vapor deposition. In: 2010 IEEE long island systems, applications and technology conference, 2010, pp 1-6

22. Wei H, Wu Y, Lun N, Hu C (2005) Hydrothermal synthesis and characterization of ZnO nanorods. Mater Sci Eng A 393:80-82

23. Lakehal A, Bedhiaf B, Bouaza A, Hadj B, Ammari A, Dalache C (2018) Structural, optical and electrical properties of Ni-doped $\mathrm{CO}_{3} \mathrm{O}_{4}$ prepared via sol-gel technique. Mater Res 21:1-8

24. Mamouni N, Vijaya J, Benyoussef A, Kenz A, Bououdina M (2018) Electronic structure and magnetic studies of $\mathrm{V}$-doped $\mathrm{ZnO}$ : ab initio and experimental investigations. Bull Mater Sci 41:87

25. Etape EP, Foba-Tendo J, Ngolui LJ, Namondo BV, Yollande FC, Nguimezong MBN (2018) Structural characterization and magnetic properties of undoped and Ti-doped $\mathrm{ZnO}$ nanoparticles prepared by modified oxalate route. J Nanomater 2018:9

26. Qi H, Glaser ER, Caldwell JD, Prokes SM (2012) Growth of vertically aligned $\mathrm{ZnO}$ nanowire arrays using bilayered metal catalysts. J Nanomater 2012:7

27. Mote V, Purushotham Y, Dole B (2012) Williamson-Hall analysis in estimation of lattice strain in nanometer-sized $\mathrm{ZnO}$ particles. J Theor Appl Phys 6:6

28. Gattu KP, Kashale AA, Ghule K, Ingole VH, Sharma R, Deshpande NG, Ghule AV (2017) $\mathrm{NO}_{2}$ sensing studies of bio-green synthesized Au-doped $\mathrm{SnO}_{2}$. J Mater Sci-Mater Electron 28:13209-13216

29. Devi PG, Velu AS (2016) Synthesis, structural and optical properties of pure $\mathrm{ZnO}$ and Co doped $\mathrm{ZnO}$ nanoparticles prepared by the co-precipitation method. J Theor Appl Phys 10:233-240

30. Strelchuk V, Kolomys O, Rarata S, Lytvyn P, Khyzhun O, Chey CO, Nur O, Willander M (2017) Raman submicron spatial mapping of individual Mn-doped ZnO nanorods. Nanoscale Res Lett 12:351

31. Wang Y, Cheng J, Yu S, Alcocer EJ, Shahid M, Wang Z, Pan W (2016) Synergistic effect of $\mathrm{N}$-decorated and $\mathrm{Mn}(2+)$ doped $\mathrm{ZnO}$ nanofibers with enhanced photocatalytic activity. Sci Rep 6:32711

32. Zhang X, Qin J, Xue Y, Yu P, Zhang B, Wang L, Liu R (2014) Effect of aspect ratio and surface defects on the photocatalytic activity of $\mathrm{ZnO}$ nanorods. Sci Rep 4:4596

33. Hezam A, Namratha K, Drmosh QA, Chandrashekar BN, Sadasivuni KK, Yamani ZH, Cheng C, Byrappa K (2017) Heterogeneous growth mechanism of $\mathrm{ZnO}$ nanostructures and the effects of their morphology on optical and photocatalytic properties. CrystEngComm 19:3299-3312

34. Chanda A, Gupta S, Vasundhara M, Joshi SR, Mutta GR, Singh J (2017) Study of structural, optical and magnetic properties of cobalt doped ZnO nanorods. RSC Adv 7:50527-50536

35. Johar MA, Afzal RA, Alazba AA, Manzoor U (2015) Photocatalysis and bandgap engineering using $\mathrm{ZnO}$ nanocomposites. Adv Mater Sci Eng 2015:22
36. Das R, Kumar A, Kumar Y, Sen S, Shirage PM (2015) Effect of growth temperature on the optical properties of $\mathrm{ZnO}$ nanostructures grown by simple hydrothermal method. RSC Adv 5:60365-60372

37. Khawal HA, Mote VD, Asokan K, Dole BN (2018) Formation of defect, oxygen vacancy creation, and shifting of phonon mode by $\mathrm{Li}^{3+}$ swift heavy ion irradiation on $\mathrm{Zn}_{1-x} \mathrm{Mn}_{x} \mathrm{O}$ thin films. $J$ Solid State Electrochem 22:1237-1248

38. Hervé $P$, Vandamme LKJ (1994) General relation between refractive index and energy gap in semiconductors. Infrared Phys Technol 35:609-615

39. Srivastava AK, Kumar J (2011) Effect of aluminum addition on the optical, morphology and electrical behavior of spin coated zinc oxide thin films. AIP Adv 1:032153

40. (2012) NIST/SEMATECH e-handbook of statistical methods

41. Pham $H$ (2006) Springer handbook of engineering statistics. Springer, London

42. Wang C, Wu D, Wang P, Ao Y, Hou J, Qian J (2015) Effect of oxygen vacancy on enhanced photocatalytic activity of reduced $\mathrm{ZnO}$ nanorod arrays. Appl Surf Sci 325:112-116

43. Putri NA, Fauzia V, Iwan S, Roza L, Umar AA, Budi S (2018) Mn-doping-induced photocatalytic activity enhancement of $\mathrm{ZnO}$ nanorods prepared on glass substrates. Appl Surf Sci 439:285-297

44. Ashkarran AA, Zad Al, Mahdavi SM, Ahadian MM (2010) Photocatalytic activity of $\mathrm{ZnO}$ nanoparticles prepared via submerged arc discharge method. Appl Phys A-Mater Sci Process 100:1097-1102

45. ArunaKumari ML, Devi LG (2015) New insights into the origin of the visible light photocatalytic activity of $\mathrm{Fe}(\mathrm{III})$ porphyrin surface anchored $\mathrm{TiO}_{2}$. Environ Sci: Water Res Technol 1:177-187

46. Ahmad M, Ahmed E, Ahmed W, Elhissi A, Hong ZL, Khalid NR (2014) Enhancing visible light responsive photocatalytic activity by decorating $\mathrm{Mn}$-doped $\mathrm{ZnO}$ nanoparticles on graphene. Ceram Int 40:100087-110095

47. Jalalah $M$, Faisal M, Bouzid H, Park J-G, Al-Sayari SA, Ismail AA (2015) Comparative study on photocatalytic performances of crystalline $\alpha-$ and $\beta-\mathrm{Bi} 2 \mathrm{O} 3$ nanoparticles under visible light. J Ind Eng Chem 30:183-189

48. Tan W-F, Yu Y-T, Wang M-X, Liu F, Koopal LK (2014) Shape evolution synthesis of monodisperse spherical, ellipsoidal, and elongated hematite $\left(\mathrm{a}-\mathrm{Fe}_{2} \mathrm{O}_{3}\right.$ ) nanoparticles using ascorbic acid. Cryst Growth Des 14:157-164

49. Rao MP, Anandan S, Suresh S, Asiri AM, Wu JJ (2015) Surfactant assisted synthesis of copper oxide nanoparticles for photocatalytic degradation of methylene blue in the presence of visible light. Energy Environ Focus 4:250-255

50. Soltani N, Saion E, Hussein MZ, Erfani M, Abedini A, Bahmanrokh G, Navasery M, Vaziri P (2012) Visible light-induced degradation of methylene blue in the presence of photocatalytic $\mathrm{ZnS}$ and CdS nanoparticles. Int J Mol Sci 13:12242-12258

Publisher's Note Springer Nature remains neutral with regard to jurisdictional claims in published maps and institutional affiliations. 